\title{
AS MINÚSCULAS REVOLUÇóES DA ESCRITURA DE JEAN RICARDOU
}

\author{
Zília Mara Scarpari Schmidt \\ Universidade Federal do Paraná
}

\section{RESUMO}

Este estı:do quer mostrar a autogeraçāo e as principais isotopias de uma coletânea de nove "novelas" interdependentes, as Révolutions Minuscules, de Jean Ricardou.

Operaçōes fundamentadas na polissemia e no anagrama engendram um texto que, por sua vez, desencadeia os textos subsequientes. A rotaçāo das palavras se projeta num movimcnto de translaçāo, efatuado pela migração dos signos de uma novela para outra, com uma reforma a cada mudança, numa semicse infinita.

O jogo das conotaçōes reflete très isotopias entrelaçadas: a isotopia constelar - percebida no mecanismo sideral das revoluçōes dos signos, a isotopia da escritura - quan. do o texto exibe e tematiza o seu próprio fazer, e a isotopia sexual ou a escritura do corpo - ir.ter-dita nas brechas do tecido textual.

Conhecido principalmente como teórico do Nouveau Ro. man francês, Jean Ricardou não dissocia, entretanto, a teoria da prática da escritura: é autor de três romances (L'Observatoire de Cannes, 1961; La Prise de Constantinople, 1965; Les Lieux-Dits. 1969) e de uma coletânea de textos breves (Révolutions Minuscules, 1971).

Contrário aos dogmas da expressão-representação e ao mito da criação ex-nihilo, Ricardou submete a sua escritura à prova do que chama de "sobredeterminação textual": a "textualidade de um elemento", isto é, sua capacidade de figurar num texto, deve ser ditada, no mínimo, por duas razōes ou, mais precisamente, por duas relações: uma, horizontal, linear, que articula o elemento escolhido à sua vizinhança; outra, vertical, translinear, que o associa a elementos mais 
distantes. Em suma, a sobredeterminação é a interseção de duas ou mais determinações. ${ }^{1}$

O processo pelo qual se obtêm as séries potenciais de elementos capazes de engendrar um texto, parte de uma base significante, à qual se aplicam duas operações fundamentadas na semelhança: a operação semântica e a operação fônica.

Uma exploração semântica abre o leque polissêmico do signo de base, seleciona determinados semas (operação paradigmática) e combina elementos do mesmo campo semântico de modo a formarem sintagmas (operação sintagmática).

O trabalho com o significante compreende a paronomásia, o anagrama, a homonímia, o "calembour" ou trocadilho, enfim, toda semelhança total ou parcial de fonemas que aproxima a série de palavras.

É neste processo de autogeração textual e na dimensão auto-reflexiva desta produção que se inscrevem os textos crí. tico-inventivos de Rêvolutions Minuscules.

A conotação sideral do termo revoluçūes (a. rotação de um astro em torno de seu eixo; $b$. movimento de um astro em torno de outro) combinada à significação microscópica e literal de minúsculas ( $a$. adj: exiguas; $b$. subst.: letras minúsculas) remete aos movimentos de rotação e translação dos signos. Estes movem-se por rotações mínimas sobre si mesmos, graças a um processo de circulação intratextual, de reflexão interna. A translação se efetua através de uma relação intertextual: os signos migram de um texto para outro, sofrendo uma reforma (anagramática e/ou semantica) a cada mudança sucessiva. Nesta alegoria sideral, o rótulo nouvelles (neuf + elles) envolve nove textos de ficção ("Jeu", "Sur la pierre". "Incident", "Lancement d'un voilier", "Diptyque", "Réflexion totale", "Gravitation", "Plage blanche" e "Autobiographie") - girando em torno de um foco feminino: a própria escritura.

Esta criculação de signos se observa igualmente na dedicatória: as Révolutions Minuscules são dedicadas a Illia, personagem da primeira novela. Palíndromo perfeito, à Illia pode ser lido indiferentemente da esquerda para a direita ou vice-versa, refletindo, neste vaivém, a reversibilidade dos textos.

O jogo das conotações propõe três isotopias 2 entrelaçadas: a isotopia constelar - percebida no mecanismo sideral

1 Ricardou, J. Nouveaux problèmes du roman. Paris. Beull, 1978. p. 244-6. 258-91. 322-35. 343-9.

2 O termo isotopia $\mathrm{vem}$ de Grelmas e pode ser definldo como a recorrência de semas contextuals nue rseceuram a homogencidade semantica do discurso. Cf. GREMrAs. J. \& COURTés. J. Sómiotique: dictionnaire ratsonné de la theorie du langage. Paris, Hachette, 1979. p. 187-8. 
dos signos, a isotopia da escritura - quando o texto exibe e tematiza o seu próprio fazer, e a isotopia sexual ou a escritura do corpo - inter-dita nas fissuras do tecido textual.

1. "Jeu"

Desencsdeadora dos textos subsquientes, a primeira novela estampa no titulo sua natureza lúdica. Jogando com o significante, jeu sugere o pronome narrativo: je. Nesta operação de homofonia, um nome se insinua: Jean (Ricardou). A novela "brinca" com a identidade do autor, que assim se pulveriza.

O texto explicita três bases geradoras ("trois prospections distinctes") ligadas "en d'étranges torsades" (p. 19).

A primeira aponta para um quadro. "Primeira" não é aqui sinônimo de origem; o texto abole, na sua estrutura fragmentária e na ambiguidade que o torna oscilante, toda lógica aristotélica, toda noção de centro, de hierarquia: "A l'origine, s'il y en eut jamais une, se dresse un tableau impeccable" (p. 14; grifos nossos).

Termo de jogo (quadro de apostas), a palavra tableau (base I) remete ao titulo e ganha conotações escriturais quando significa superficie onde se escreve (quadro-negro, tábua, prancheta).

A concepcāo de texto como uma rede de relações se desprende do seu sinônimo. toile (tela, tecido). Um jogo paronomástico produz voile (toile voile), cuja conotação marinha (vela, veleiro) relaciona-se com uma paisagem à beira-mar. Significando véu, suscita os detalhes da pintura, o verniz, a película brilhante que a envolve, cujos efeitos reflexivos ( $p$. 14) propiciam o desdobramento especular do quadro e do seu tema mitológico ("A morte de Procris", uma jovem ferida no pescoço, ao lado de um cão e de um fauno), na sensual banhista de biquini (Illia), figura mitológica dos tempos modernos.

A conotação erótica de voile (que lembra a dança dos véus) multiplica no texto (que também é tecido e corpo velado) transparências e cintilações. E o jogo da sedução, que está "na intermitência da pele que cintila entre duas peças", na ambiguiidade da "apariçāo-desapariçāo": e que reflete uma operação sensual: a leitura-desvelamento.

Confessa o texto, de modo ambiguo ("hypothèse pourtant inacceptable"), a natureza linguiistica do impulso gerador da paisagem marinha. Trata-se do "gosto imoderado" pelo Subjetivo Imperfeito, "tão fértil em a, s e e" e pelo su- 
fixo -(s)able de certos adjetivos onde subjaz a palavra sable (p. 22-23). Esta segunda base encontra, portanto, a conotação marinha proposta igualmente pela base I (tableau / toile/ voile). E então, uma nova operação fônica engendra os termos-signos do ato de escrever:

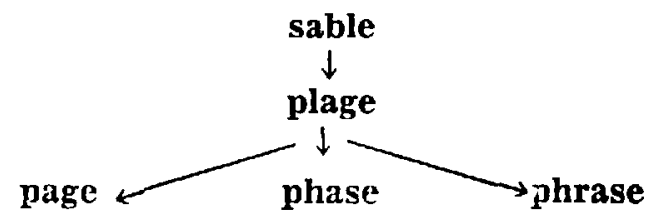

Nos pares paronomästicos (plage / page, phase / phrase) e homofônicos ( coquille: concha e erro tipográfico ou troca de uma letra por outra), aglutinam-se a dimensão referencial do texto e a dimensāo crítjca de sua construção (grifos nossos):

Je ne conterai guère, en l'extrême détail de leurs péripéties, toutes les phases qui m'ont ouvert l'accès de cette plage où, à presque l'atteindre, me voici, parmi les coquilles, proche de l'objectif (p. 13).

Mais je ne compterai guère, en l'extrême détail de leurs péripéties, toutes les phrases de cette mise au point (p. 28-29).

Cependant, peu à peu, en dépit des péripéties inlassablement contées et du recours de phrase en phrase, à maint sortilège rhétorique [...] elle s'enfuit en tous sens sur la page, parmi les coquilles... (p. 30-31).

Enfim, "une rêverie excessive avec les syllabes Piero di Cosimo" (p. 28) constitui a terceira base geradora.

Pela tradução do it. Picro, o texto obtém o substantivo comum pierre.

Remetendo à arte litográfica, ao ato de gravar, de imprimir, pierre, sinônimo de quadro-negro (retângulo de ardósia) estabelece relaçāo com a base tableau.

Entendida como material de construçāo, base, fundamento, a palavra arquiteta, no nível referencial, um paciente edificio sobre um corpo feminino ("j'entreprends de placer, avec le pouce et l'index, sur la peau très sensible, toutes sortes de pierres", p. 29), que outra isotopia pode ler como a construção da escritura no "corpo" textual. 
Assim como as pedras erigem um edificio, um texto se faz com palavras. $E$ o que parece dizer o nome do pintor florentino, através de uma traduçāo e de um curioso jogo de homófonos combinando línguas diferentes (p. 28):

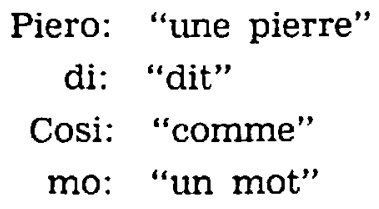

Por uma coincidência bizarra, o nome de Piero di Cosimo já contém todas as letras do nome da personagem mitológica que retrata:

\section{PIERO di CoSimo $=$ PROCRIS}

Extrapolando este anagrama estranhamente acidental, obtém-se, a partir dos mesmos elementos fônicos, o nome do pintor fictício:

\section{PROCRIS \\ PIeRO di CoSimo \\ C. PIRROS}

Combinando engenhosamente as três bases, o texto produz um crime inter-dito. Associada a Procris tanto do pontode-vista do significado (ligação metonimica entre o pintor e a obra) quanto do significante (a obra como anagrama do nome do pintor), a base III (Piero di Cosimo) engendra a vitima a partir de uma operação anagramática: Procris proscrit corps pris (p. 26-27).

Proscrit é atributo do criminoso, hipótese confirmada pela sobredeterminaçāo que the confere a leitura mitológica: Céfalo, esposo de Procris, foi proscrito e banido por tê-la matado involuntariamente, curante uma caçada. ${ }^{+}$A palavra contém ainda cri (grito) e (é)crit (escrito), conjugando escritura e violência. Em corps pris, o verbo prendre adquire o significado de apossar-se, possuir, violentar. E se a violência está implicita em Procris, a escritura do corpo também subjaz no nome do pintor: Piero produz pierre por tradução; seu sinônimo roc, que integra uma paisagem rochosa ( $p$. 22-23), é um anagrama fonético de corps, donde a seguinte rede analógica:

4 Grimal. P. Dictionnaire de la mythologie. 6.e. Paris, Presses Universitalres de Fran Ce. 1979. p. B5: 


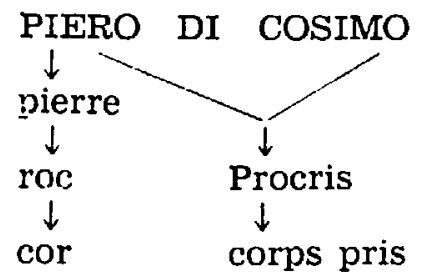
Illia.

Justifica-se, agora, porque o duplo de Procris se chama

Lembrando foneticamente Ilion (Tróia), Illia projeta a dimensão do desejo. Sobredeterminada pela mitologia grega presente na tela, Ilion remete a uma mulher cobiçada: Helena. Assim, a versão guerreira da tomada de Tróia ("la prise d'Ilion") reflete a versão sexual da "prise d'Illia", ou seja, de um "corps pris".

Sendo cultura, a linguagem se fundamenta no interdito. A escritura corporal de "Jeu" violenta a linguagem, desvelando-lhe o espaço proibido do desejo.

Escrever é um manejo voluptuoso: “j'entreprends de placer, avec l'index, sur la pente sensible, toutes sortes de lig. nes. De temps à autre, je lève les yeux" (p. 26). Do contato afetivo e sensual com as palavras, o texto se delineia como matéria, corpo erótico: "j'ai levé les yeux: une frange de soleil soulignait, sur la peau ruisselante, les contours très osés du corps" (p. 29). Nele se percebem, subrepticiamente, "les parfaites inflexions de la chair" (p. 19, 25).

"Jeu" inscreve o defloramento da página virgem ("unitaire couleur d'une pente immaculée", p. 17) pela escritura que a insemina e que faz dela um espaço autogerador de significações. Neste sentido, a primeira novela é, literalmente, um texto de "abertura": a frase rasga e macula a página ("je ne compterai guère, en l'extrême détail de leurs péripéties, toutes les phrases qui m'ont ouvert l'accès de cette plage... p. 13; grifos nossos), inaugurando as Révolutions Minuscules.

A conotação sideral deste titulo, estendendo-se aos textos que ele engloba - em número igual ao dos planetas de nosso sistema solar, indica a presença de uma isotopia as. tronômica que se amplia gradativamente, com o entrelaçamento das novelas.

Apontada pelo nome Orion (p. 28), a isotopia constelar de "Jeu" desvela-se na "dispersão volátil" dos signos.

Quatro estrelas formando um quadrilátero encerrando três outras dispostas em linha oblíqua (o "Boldriê) compõem a constelação de Orion. O quadrilátero é designado comu- 
mente por "ombro cireito de Orion" (astro Alfa ou Bétel geuse), "ombro esquerdo" (Gama ou Bellatrix), "joelho direito" (Kappa) e "pé esquerdo" (Beta ou Rigel). Esta desig. nação metonímica (Lévi-Strauss assinala a percepção indigena de Orion como um corpo mutilado ") se reflete na construção fragmentária do corpo de Procris Illia: "épaule ou avant-bras gauche" (p. 15 e 18), "jambe gauche", "pied", "genou droit" (p. 16), etc. Neste contexto, Sirius, ligado a Orion (em "Jeu", Orion se substitui ao seu cão Sirius), pode ser lido como um anagrama de Osiris, cujo corpo desmembrado representa a estrutura nāo linear do texto. Mas o mito de Osiris não se resume nisso: um fragmento do Deus escapa à recomposiçāo tentada por Isis (evocada na palavra iris, p. 18): o pênis. O Boldriê, também chamado de "Bastão Branco" ("Baguette Blanche"), seria o membro cortado.

Ao sul do Boldriê, um filete de três estrelas menores forma a "Espada de Orion". A arma entra em conexão com o ferimento de Procris. Espada e bainha integram-se na isotopia sexual.

A direita do "ombro esquerdo" da constelação figura, em linha curva, um escudo ("le Bouclier"), visto igualmente como uma genuflexāo paralisada, ${ }^{8}$ o que o texto de Ricardou parece confirmar: "En revanche, le genou droit quelque peu se levait et l'appui, en conséquence, exigeait que le pied se haussât jusqu'à l'extrême de sa cambrure" (p. 16-17).

As aves pernaltas da tela ficticia ("des minces échas. siers", p. 14, 20,27) completam a remissāo a Orion, também denominada "Echassier"."

Nome dado a "un jeune chien" (p. 28), imagem duplicada do cão de Procris, Orion agrupa, com sua referência implícita ao grupo estelar do Cão Menor e do Cão Maior, uma série de significaçōes siderais. Ao cão de Procris se liga, anagramaticamente, a estrela principal do Pequeno Cão: Procyon.

A pluralização dos cães e a palavra chenil (p. 14, 21, 27) remetem, por sua vez, a uma outra constelação: à dos Cães de Caça (ou "Lévriers")." A do Pequeno Triângulo "1 aparece implicita no "menu triangle du slip". A do Corvo ou Garça Voadora ("le Héron Volant") ": insinua-se nos desenhos de um tecido "estrelado":

5 AUGE, $P$. Detionnaire Larouse du XXe. sizcle. Parls, Lasousse, 1928, v, 5, p. 246.

G LEVI-STRAUSB, C. Astronomie blen temperee. In: - _ Le cru et cuit. Parts. Plon. 1964. p. 226-30.

7 LEVI-STRATSS. D. 228

8 LEVI-STRAUSB, D. 229.

9 LEVI-STRAUSS. D. 228 .

10 AUGE, Y. 2, D. 214.

LEVI-STRAUBg. p. 236. 
Des plis imperceptibles étoilaient, du pubis jusqu'à l'élastique, le menu triangle du slip [...] Les des. sins s'y montraient à present bien lisibles: des hérons en vol et à l'arrêt (p. 26-27; grifos nossos).

A abundante cabeleira esparsa descrita insistentemente (p. 15, 18, 25, 31), representa fios que urdem significaçōes: "chevelure" pode referir-se tanto a um cometa, "astre chevelu", quanto à constelação conhecida como Cabeleira de Berenice. ${ }^{13}$

Um novo trabalho anagramático tece novas relações: "Pour toute désobéissance, il sut bientôt connaître l'étendue de sa disgrâce à une ciscrète marque d'infamie: l'octroi du nom Noiraud" (p. 28). Orion Noiraud, contendo nas suas letras a cor negra (noir), inverte o cromatismo das constelações siderais (Orion é "brun", a cabeleira näo é luminosa, mas "sombre"), lembrando que "on n'écrit pas, lumineusement, sur champ obscur, l'alphabet des astres [...] l'homme poursuit noir sur blanc". ${ }^{14}$

2. "Sur la pierre"

Sobre uma superfície rochosa banhada pelo mar, três tipos de algas, um corpo feminino e o retalhamento de um molusco por um caranquejo constituem o estofo diegético de "Sur la Pierre" (S.P.).

A cena de esqui aquático envia ao campo semântico de vela, esporte marítimo (base tableau: toile / voile). A lancha ("canot automobile") deriva da homofonia entre canaux ("Jeu", p. 24) e canot.

A superfície rochosa, remontando a Plero di Cosimo (pierre), gera o corpo feminino (roc/ corps).

Illia se transforma agora num gênero de crustáceo decápode braquiúro (ilia é seu nome científico)..$^{15} \mathrm{O}$ mexilhão parece metamorfose semântica de concha ("coquille", p. 13, 24 e 31 ).

A isotopia constelar, indicada pela inscrição luminosa em superfície escura ("La peau, très bronzée, et les triangles du tissu rose à pois blancs sont constellés d'auréoles de sel", p. 44), bem como pela cabeleira loura e brilhante secando ao sol (p. 37) ou solta ao vento ( $p .39$ ), lembrando um cometa ou a "Cabeleira de Berenice", permite ver no crustáceo uma constelação zodiacal: Câncer. Na constelação sígnica do texto, Câncer aproxima-se de Orion, através do

13 AUGE, V. 2, D. 206.

14 MALLARME, B. Oeuvres complètes. Paris. Gallimard 1945. p. 370.

IG AUGE, V. 4, D. 16. 
nome "Carapaça" pelo qual também ć conhecido o seu escudo. ${ }^{16}$

As três variedades de algas desvelan a escritura co cor. po. Como as "três prospecções distintas" (p. 19-20), a primeira variedade é formada de filamentos "liés en torsades" (p. 35) que se colam à pedra e "en épousent la forme". Mais adiante são cabelos "agglutinés en torsades mouillés" (p. 37), que escorregam pelo ombro direito "dont ils épousent la forme" (p. 42). O segundo tipo são algas escuras e escorregadias, conotando a região pubiana e a paisagem sexualizada de "Jeu" ("pelouse", "touffe de graminées", "végétation incontrôlable", "buissons"): "une frange de poils noirs a poussé en tapis velouté, mince, très glissant" (p. 36). Enfim, existem as "ulves transparentes depliées, gorgées d'eau" (p. 45), cuja alusão ao sexo feminino é feita nāo só pela sua forma em gomos mas, sobretudo, pelo jogo anagramático ulve / vulve. Gorgées deriva de gorge, remetendo à jovem agonizante da tela de C. Pirros

"Coquille de moule" (p. 39) é um elemento duplamente erótico: se "coquille", eriquanto dobra, é um símbolo sexual, ${ }^{1 \pi}$ o molusco e suas valvas se ligam ao corpo feminino por meio de uma operação fônica:

\section{algues valves \\ ulve / vulve / valve}

A paronomásia vulve valve erotiza a descriçāo: "Des lambeaux ce chair jaune adhèrent encore à la face intérieure des deux valves écartées" (p. 39 ).

Repasto do caranguejo, o molusco se configura como um novo "corps pris", enquanto os movimentos do crustáceo, "les pattes centrales posées sur les deux valves nacrées" (p. 40) do mexilhão que "tangue à droite et à gauche, par saccades" (p. 42) traem o ato sexual, "en une série de mouvement secs et précis" ( $p .40$ ). Na isotopia da escritura, a trajetória particular do caranguejo e a sua ação de retalhar e deglutir o molusco constituem a auto-representação do texto concebido como um corpo nāo linear, fragmentado, assimilador de outros textos.

\section{3. "Incident"}

O título da novela insinua os incidentes de uma escritura subversiva. Além das conotações politicas, a diegese inscreve "o conflito das cores" (p. 49) ou, mais precisamen-

17 Cr. PAZ. O. Signos em rotacão. Săo Paulo, Perspectiva, 1976. p. 190 
te, a oposição do preto e do branco, metáfora da escritura (a tinta e o papel), de seu espaçamento, de sua diferença.

Conceito emprestado de Mallarmé, ${ }^{1 *}$ o espaçamento designa o espaço constituído entre termos, a intervenção regular do branco no texto (pausa, pontuação, intervalo em geral). Em termos derridianos, adquire uma significação ativa de "força produtiva, positiva, geradora" (espaçamento como "différance"), que faz com que um elemento só funcione e signifique a partir de sua inter-relação com outros elementos. ${ }^{19}$ E também este sentido que subjaz na novela de Ricardou: nenhum signo da ficção tem valor por si próprio, mas a partir da rede de relações que ele estabelece com os demais.

O "conflito das cores" diz respeito ao intertexto de Mallarmé, onde se cruzam a tipografia e o alfabeto estelar.

Numa esquina, um edifício enegrecido contrasta "sa crasse ardoisée" com o "calcaire osseux" das paredes recémlavadas de outro imóvel (p. 49). Não é difícil perceber então, na ardósia e no calcáreo, o quadro-negro e o giz, remetendo à base tableau ("Jeu").

A partir daí multiplica-se o jogo do preto e do branco, num processo de mil inversões: rachaduras se inscrevem, sombrias, nas paredes claras (p. 49). Com a lavagem dos edifícios, o branco vai ganhando aos poucos a fachada enegrecida, enquanto o asfalto é constelado com os jatos da mistura detergente de água e areia (p. 51-52). O conflito das cores se prolonga nos relevos de uma gigantesca estátua, um atleta de pedra - nova configuração do gerador Piero ("Jeu"), seja num jogo de luz e sombra, seja no contraste mais claro da pedra com a sujeira acumulada nos vãos (p. 50). Nos olhos inertes da estátua ("les yeux bombés de la statue", p. 50), a isotopia constelar permite ler nova referência a Orion, reiterada pela cegueira momentânea do transeunte / operário, provocada pela areia que o vento carrega numa "cintilação vaporosa" (p. 52) e pela agressāo dos anarquistas (p. 54). No seu braço horizontalmente estendido, um pombo é determinado pela semelhança fônica que liga pigeon a bour. geon (elemento do jardim público) e bourgeron (roupa de operário). Ora voando, ora pousado, o pássaro é também elemento de "Jeu", mais precisamente dos desenhos do biquini: "des hérons en vol et à l'arrêt" (p. 27).

Silhueta clara contra as paredes escuras, sombria contra o prédio lavado ( $\mathrm{p}$. 55), a ave desenha trajetórias luminosas ao sol e escuras na sombra. Seu vôo complexo dá asas à ima-

18 Mallarmi: D.3B7 e 455.

19 DERRtDA, J. Marges de la plilosophic. Paris, Minult, 1972. p. 8-29. Positions. Paris. Minult, 1972 , D. 38, $107-9$. 
ginaçāo em preto e branco; as metamorfoses de sua trajetória ilustram a transformaçāo dos signos no processo da escritura; circulos e elipses evocam as órbitas destes signosastros (p. 55). O ponto de partida do vôo é necessariamente o punho, a māo fechada da estátua (sobredeterminada pelos homófonos point / poing), onde se fixa uma pena, instrumento fálico da escrita, desprendida do pássaro, este "porte-plume". Com seus volteios sinuosos, ela lembra a "plume solitaire éperdue" de "Un coup de dés".

Enfim, inscrições murais incessantemente reformadas pela subversão das palavras configuram o processo do palimpsesto, onde o jogo do preto e do branco projeta uma vertiginosa "mise en abyme".

Numa das inscrições murais, a cruz encerrada na vogal inicial da palavra occident (p. 52) remete aos quiasmas da escritura (inscritos microscopicamente no $\mathbf{x}$ das palavras jeux, yeux. heureux, osseux, fixes, oxydé), bem como à nona letra do alfabeto hebreu ("têt" ou "têth" um $t$ articulado com ênfase). No alfabeto fenício, era grafado exatamente como um círculo circunscrito a uma cruz, protótipo do "tetha" grego. ${ }^{20}$

O nome da letra é feito hipograma no significante athlète (p. 50). Designando provavelmente serpente, ${ }^{, 1}$ conforme indica a grafia da letra hebraica, a palavra têt amplia a rede constelar dos signos: simbolo fálico, esperma, cometa, serpente mordendo a própria cauda, representa o funcionamento textual, a circulação e a autofecundação das palavras. A remissão ao ouroboros metade preto, metade branco, ${ }^{22}$ envia ao jogo da tinta e do papel que fundamenta a novela. Enfim, próximo de têt e tetha, tetra sobredetermina o número 4 em que se baseia a novela, e o quadrado ("square", "quadrillage", "carreaux", p. 50 e 51), forma do ideograma chinês que significa escrever.$^{2.3}$

\section{4. "Lancement d'un voilier"}

Embora o título pareça referir-se a uma única cena, a diegese se constrói com dois motivos sugeridos pela polissemia da palavra lancement: o lançamento de um veleiro ao mar e um jogo de arremesso.

O contexto marinho e o elemento voilier remetem à base geradora -(s)able e à dupla fono-semântica toilc / voile da base tableau. $O$ jogo de arremesso e os jogadores, "des pê-

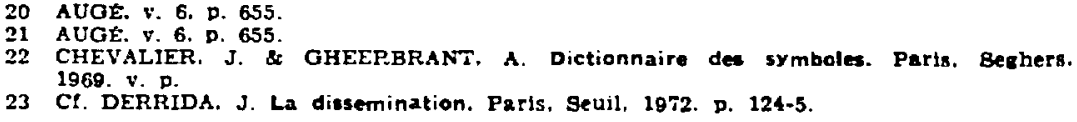


chcurs problablement" (p. 66), parecem decorrer de jeu e de Piero di Cosimo, que pode transformar-se num nome bi. blico (Simão dito Pecro, o pescador):

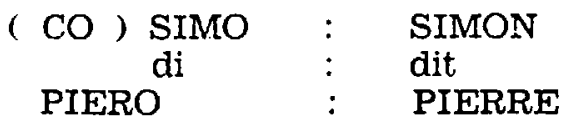

A mistura detergente arremessada contra a parede em In. e a paronomásia jet / jeu encontram correspondência no jogo de arremesso. $O$ jato de água e areia remove das paredes a crosta negra. Ao muro descascado corresponde simetricamente o casco descamado de um velho navio. Um processo de inversão prolonga em "Lancement d'un voilier" (L.V.) o conflito das cores que estrutura a novela anterior: removida a sujeira, o branco se desvela na parede; o casco, ao contrário tem o branco removido, sob o qual a cor negra é entrevista. Depois, as imagens se correspondem num paralelismo: pequenos tufos de ulvas brancas (elementos de S.P.) pontilham a quilha negra do veleiro, da mesma forma que o betume do chão é granulado de branco pela areia da mistura detergente.

A embarcacão, com suas diversas partes nomeadas ("voiles", "poupe", "carène", "mât"), lembra a constelação de Argo ou navio, onde se reconhecem igualmente as velas, a popa, a quilha e o mastro. ${ }^{24}$

Sobre a via férrea, o "immense chariot rectangulaire" que sustenta o veleiro em reparação (p. 64) reproduz a imagem da Grande Ursa, também chamada de "Grand Chariot". $\mathrm{Na}$ estrutura de madeira que suporta a embarcação ("échafaudage", "poutres", "cales de bois", p. 69), mais uma vez Orion parece referido: um de seus muitos nomes é "Echaffaudage". 25

Nesta alegoria sideral, as novelas formam um sistema planetário. Como no jogo ao ar livre, progredindo indefinidamente ("de jeu en jeu ils se dirigent vers le haut de la plage", p. 71), cada texto em rotação se projeta parabolicamente nos outros, em torno dos quais efetua um movimento de translação.

\section{5. "Diptyque"}

O termo díptico designa, originalmente, um objeto constituído de tábuas duplas que se abrem e se fecham como um livro. Sobre elas eram gravadas antigas inscrições com esti- 
lete, ou pinturas medievais e renascentistas. O termo estendeu-se à obra literária composta de duas partes iguais que se correspondem em relação simétrica de semelhança ou inversāo.

E o caso da novela intitulada "Diptyque" (D.): divide-se em dois capitulos distintos e simétricos, articulados por elementos comuns, fazendo com que as duas partes se fechem uma sobre a outra. Citação de si própria, D. estende sua intratextualidade a um intertexto mais amplo, onde se reconhecem, naturalmente, citaçōes das outras novelas, bem como referências a inúmeros outros textos, numa composição que lembra o "puzzle".

Estendendo sua estrutura dual a todo o volume, D. faz das Révolutions Minuscules um livro composto de textos que se abrem e se fecham uns sobre os outros.

Ocupando exatamente o centro do conjunto arquitetado de nove novelas, $D$. divide o volume em duas partes iguais, compostas de quatro textos cada uma. Enquanto charneira, estabelece uma articulação (ou costura, "reliure") entre a primeira e a última novela, entre a segunda e a oitava, entre a terceira e a sétima e entre a quarta e a sexta. Nesta correspondência translinear, há um movimento de inversão e rotação retorcida que poderia ser figurada pela banda de Moebius.

\begin{tabular}{|l|l|l|}
\hline 1. Jeu & & 9. Autobiographie \\
\hline 2. Sur la pierre & . & 8. Plage blanche \\
\hline 3. Incident & A & 7. Gravitation \\
\hline 4. Lancement d'un voilier & is & 6. Réflexion totale \\
\hline
\end{tabular}

"Plage blanche" reintroduz o contexto essencialmente marinho de "Sur la pierre", com a qual partilha a citação do mesmo romance: L'Observatoire de Cannes. "Gravitation" e "Incident" se assemelham através da paisagem urbana e de "palavras cruzadas". "Réfiexion totale" comporta, como "Lancement d'un voilier", estrutura essencialmente especular.

Enfim, unidas pela identidade do pronome narrativo ("je") que lhes confere um caráter testemunhal, mas sem pessoa - é a escritura contando a sua própria aventura "Jeu", "Diptyque" e "Autobiographie" formam um eixo estrutural: "Jeu" é a novela desencadeadora dos textos subse- 
quientes; "Autobiographie", uma espécie de síntese da produção ficcional do autor e "Diptyque", a "mise en abyme" de um livro aberto ao meio: as Révolutions Minuscules.

\section{6. "Réflexion totale"}

Definida como um sistema de efeitos especulares, a reflexão se manifesta na diegese através de uma superfície aquática que projeta uma série de desdobramentos, a começar pela inversão total da paisagem: "Plus loin, c'est le miroir absolu où tout est renversé" (p. 102).

Espelhada na superfície lisa, uma teia de aranha - já mencionada em D. (imagem da autofiação do texto), e agora entre as ảrvores, numa "succession de polygones concentriques sans cesse élargis" (p. 104) - tem sua duplicação clevada ao segundo grau, quando as ondas provocadas na água pela queda de uma pétala refletem a reflexão da teia (p. 100 a 105).

Os reflexos se mostram igualmente nos pares sinoními. cos (étang - mare, piéride - papillon, têtard - embryon, vase - limon ). Também o significado é duplicado por anagramas (étoile / pétiole; étale / pétale), paronomásias (mare / miroir, ellipse / eclipse), homônimos (soies / soit).

Variante do caranguejo a retalhar e deglutir o molusco (S. P.), a aranha prende em seus fios uma borboleta, vinculada à base III de "Jeu" graças a uma analogia fônica (piéride / Piero), novo "corps pris" absorvido freneticamente.

O corpo da aranha combina cruz e circulo ("la croix blanche tracée sur l'abdomen", p. 104), outra sugestão da palavra têth, introduzida na terceira novela. Serpente, esperma ou embrião, o nome associa-se fônica e semanticamente a têtard (p. 105).

A forma embrionária parece subentendida igualmente em "Jeu", no significante chenil (p. 14, 21 e 27), próximo de chenille (larva).

O elemento nymphéa que integra a paisagem aquática de Réflexion totale" (R. T.) contém o embrião de outro signo (nymphe) que, por sua vez, já é semanticamente "larva": hipograma gerador de significaçōes e termo zoológico, ninfa é a forma intermediária entre a larva e o inseto adulto ao qual o texto faz referência (têtard).

O sentido anatômico da palavra ninfa (pequeno lábio da vulva ), unido ao de nenúfar branco, desvenda uma hábil transformação das algas antropomórficas de S.P.: 

S. P.
R. T.

ulve $/$
vulve $\quad \begin{aligned} & \text { dépliées (p. 45) } \\ & \text { blanchies par le soleil nymphéas } \\ & \text { déssechées (p. 36) nymphe }\end{aligned}\left\{\begin{array}{l}\text { étalés (p. 101) } \\ \text { pétale blanc. } \\ \text { convexe, } \\ \text { à demi séché } \\ \text { (p. 104) }\end{array}\right.$

Mais adiante, completando-se a metáfora estrutural da metamorfose, surge "ailes battantes, plus haut, plus bas, une piéride blanche" (p. 106), imagem da hesitação, da ambiguiidade dos signos, do zig-zag livre das palavras no seu "miroitement volatile", como assinala Mallarmé. ${ }^{26}$ Citando "Quant au livre", a borboleta reflete o próprio livro:

\section{papillon / papier + piéride blanche $=$ page blanche $\{$ livre.
ailes battantes: diptyque}

Enfim, a ambigüidade semântica das palavras robe (asa de borboleta e vestido) e nue (nuvem e nua) provoca a mudança do inseto em mulher. Na reflexão enganosa e sensual das palavras se vislumbra ora vestida ("robe"), ora despida ("nue"), a silhueta que "s'arrête au bord de l'eau, légère, interdite" (p. 108).

Com a imagem mallarmaica da espuma, renda flutuante e invisivel (variante da teia de aranha, transparente e esvoaçante), o texto se propōe, mais uma vez, como renda de significaçōes transcendendo o referencial e o linear, para revelar-se no inter-texto. Trançado por um feixe de signos que sempre contêm, em germe, outros signos, ele é "ce pli de sombre dentelle qui retient l'infini". ${ }^{2 i}$

\section{7. "Gravitation"}

Uma brincadeira infantil (a amarelinha), dois jogos de palavras cruzadas e a leitura simuliânea de um jornal, de uma revista e de um livro fundamentam a diegese desta novela.

Remetendo à lei da gravitaçāo universal, o título desencadeia uma isotopia física e astronômica que se cruza com a da escritura.

Conotada na dedicatória ("Pour Ursula Sephira..."), a constelação da Ursa, também chamada de "Grand Chariot" (já referida pelo "immense chariot rectangulaire" de L.V., p $64)$, reflete-se no carro cintilante de "Gravitation" (G.). 
A pequena Ursa sugere, pelo adjetivo ("Petite Ourse"), a menina da amarelinha ("petite fille"), cuja cabeleira abundante e sinuosa, "retenue par un ruban de velours rose" (p. 125) trai a rede constelar dos signos: a Cabeleira de Berenice, a Ursa (vel- ours) e o jogo da escritura (lat. vel + ludus), fundado na oscilação, na hesitação, na ambiguiidade (lat. vel: ou... ou, talvez). As sete estrelas principais que compõem a constelação sugerem o sistema numérico da sétima novela.

"Par sauts successifs sur le seul pied droit" (p. 120), a garota lembra, ainda, "Orion unijambiste", cujo boldriê também figuraria a perna decepada. ${ }^{28}$

$\mathrm{Na}$ constelação das palavras, lune, "cet astre bouleversé" (p. 123), se subverte e se eclipsa por detrás de anagramas: nul (p. 135), ulne (nas palavras cruzadas).

Além do título, certas palavras evocam a lei de Newton, segundo a qual a matéria atrai a matéria na razão direta de suas massas e na razão inversa do quadrado de suas distâncias:

Divers nuages blancs sont répartis dans l'espace. Tournant lentement sur eux-mêmes, ils s'y meuvent, et modifient continument, avec leurs contours, leurs masses et leurs distances respectives (p. 14; grifos nossos).

Esta lei parece aplicar-se ao principio da analogia que fundamenta o processo de autogeraçāo das novelas.

$\mathrm{Na}$ translação dos signos, a amarelinha faz remontar a "Jeu": marelle provém etimologicamente do pré-romanço marr., que significa pedra 19 (Cf. Piero, pierre, base III).

Automobile vincula-se a canot automobile (S.P., p. 40). Uma correspondência de detalhes une o carro de $G$. à carreta e ao veleiro de L.V.:

L. V.

chariot

coque

cale sèche

coque rigoureusement
G.

- $\quad$ voiture

carrosserie déjà sèche voiture en stationnement (p. 114).

A palavra wagon (p. 130), que evoca metonimicamente a viagem de trem, é imagem transformada do carro-vagão que sustenta o barco da quarta novela (p. 64-65). A bola de

28 Cl, LEVI-BTRAUSB, p. 299-31.

29 ROBERT. P. Dictionnaire alphabetique et analogique de la langue francaise. Parls, Société du Nouveau Littré. 1970. D. 1044. 
aço do jogo ao ar livre (L.V.) se transforma na pequena lata de graxa ("boite de cirage", p. 116) que serve cle "palet" ao jogo da amarelinha. A metamorfose parece provocada por um anagrama (acier / cire) e reencontra em graisse (p. 64) seu sinônimo.

O título da seção do jornal reservada às palavras cruzadas envolve um trocadilho bilíngìe sobredeterminado pela evocação da língua inglesa (na referência a Faulkner): o fr. monnaie (R.T., p. 102) no inglês é coin (moeda), graficamente idèntico ao fr. coin (canto, ângulo). Deste cruzamento bilinguie parece surgir o "Coin des Cruciverbistes" (p. 121).

Dentre as muitas semelhanças que aproximam $G$. de In., há o mesmo jogo explícito com os signos verbais: em In., um transeunte se diverte subvertendo as inscrições feitas no muro, graças à superposição engenhosa de caracteres ( $p$. 52-53); em G., dois personagens se distraem com palavras cruzadas. O formato da amarelinha remete à cruz no interior do círculo inicial da palavra occident (In., p. 53). Este "o croisé" contém, subliminarmente, "mots croisés". Às inscriçōes primitivas dos muros, já tênues (In. p. 52-53), corresponde o traçado anterior da amarelinha, esmaecido pela chuva (G., p. 115). Alusāo ao palimpsesto: em In., as emendas feitas nas inscriçōes oferecem uma superposiçāo de letras (p. 52-53); em G., a palavra ciel deixa transparecer as hesitaçōes da grafia anterior (p. 119).

Ambas as noveias terminam com a mesma imagem: "le journal froissé", semidestruido (o primeiro pelo fogo, p. 58; o segundo, pela água, p. 138). Com a chuva, a tinta das palavras cruzadas se dilui no jornal abandonado, configurando um novo "heurt des typographies" (In., p. 59).

\section{8. "Plage blanche"}

A partir de um jogo de palavras implicito no titulo (plage blanche page blanche), a oitava novela diz a sua própria construção no espaço branco da página.

O texto se constrói sobre três bases (como "Jeu"): um castelo à beira-mar, um espaço branco (plage / page) e a atividade de um empregado da limpeza pública, que maneja um rastelo.

Atualização diegética de uma inscrição reformada ("Audessous des palais, la plage" - In., p. 52), o castelo representa o edifício do texto. Suscetível à erosão e descrito a par. tir de seu reflexo na água que uma brisa anima (como as imagens refletidas de R.T.), ou de sua sombra sujeita à mobilidade com o passar das horas, projeta a instabilidade dos 
signos, que um simples deslocamento pode transformar. Ele próprio é todo construído de uma reforma de palavras:

$\begin{array}{llll}\text { Repetiçāo: } & \text { arêtes } & - & \text { arêtes (D., p. 80) } \\ \text { Sinonímia: } & \text { image cramoisie } & & \text { pierres rouges ("Jeu" p. 30) } \\ \text { Polissemia: } & \text { tours } & - & \text { tour à tour ("Jeu", p. 30) } \\ \text { Derivaçāo: } & \text { créneaux } & - \text { (nuages) } & \text { crénelés (S.P., p. 43 } \\ \text { Paronomásia: créneaux } & - & \text { canaux ("Jeu", p. 24) } \\ & \text { merlons } & - & \text { merle (D., p. 91) } \\ & \text { pont-levis: pont } & - & \text { point (em todos os textos) } \\ \text { Anagrama: } & \text { levis } & - & \text { ville (G., p. 124) }\end{array}$

O rastelo reintroduz a constelação de Orion, também conhecida pelo nome de "Râteau". ${ }^{30}$ Castelo e rastelo se associam num jogo fônico (château / râteau). A trajetória desenhada na areia pelo instrumento é um "itinéraire méthodique" (p. 147), como a escrita, ligando-se ao "fin graphisme" produzido pelas pegadas dos pássaros (estes "porte-plumes") impressas no solo (plage / page, p. 143-144).

A praia se desdobra na configuração da página. Daí o uso regular dos espaços em branco. Esta técnica mallarmaica faz do texto um poema, com o lirismo acumulado nas frases nominais:

"A chaque fois, des paysages: les oiseaux fragiles, dès le jour" (p. 143).

Um "verso" proclama na polissemia de um signo (vers) a translinearidade do texto:

"Vers le soir, lecture renversée" (p. 153).

Gerado por uma série de metamorfoses (envers - In. / versos-D. / avers / revers - R.T. / averse - G. / inverse / renverse verse / vers - P.B.), sobredeterminado pelo caráter poético e pelas incessantes repetições testemunhadas numa metalinguagem ("Les redites abondant, et les mots épars que nul lien n'accorde, semble-t-il", p. 153), o signo vers estrela o texto de muitas conotações. Preposição indicando sentido, direção, reflete o movimento do texto em direção ao infinito da linguagem; este é o seu "sentido". Graças à etimologia latina, a palavra remete duplamente à isotopia da escritura: anquanto sulco, traço (versus, -us), desig. na a linha da escrita; enquanto ação de voltar, de retornar com o arado (versare), conota o vaivém do translinear. Daí sua relação com o rastelo: "à la fin de la plage, l'homme

30 AUGE, v. 5, D. 246. 
impose demi-tour à l'outil" (p. 146-147). Por isso, logo apos este "verso", o texto é "renversé" e retoma as imagens iniciais.

Da aproximação de duas frases simétricas e enigmáticas surge nova significação metalinguística:

"Pangrammatisme: à l'initiale on multiplie les a" (p. 145)

"C'est la nuit: on multiplie les algues" (p. 155).

Algas são filamentos que, ligados à frase anterior, completam a palavra incógnita cuja inicial também é a (Esta letra envia curiosamente ao objeto a de Lacan, referindo-se à mãe, desejo primordial interdito).$^{31}$ A metáfora da escritura se completa, formando uma rede de relaçóes, ou seja, o paragrama de que fala Kristeva: modelo tabular, não linear do texto, onde cada elemento funciona dinamicamente para a produção de sentidos.3: Pangrammatisme, paragrammatisme. O neologismo de Ricardou, porém, é mais rico: se o grego pan (tudo) + gramma (letra, escrita, grafia) gera um termo que convoca a disseminação da escritura, o francês pan (pedaço de tecido) reitera no próprio vocábulo a sua noção de texto.

Um jogo amoroso é explicitado:

Rires, jeux, éclaboussures, poursuite en contrebras. Et elle, brune dans l'écume, l'eau à mi-jambe, essaie de fuir. Elle crie non, non, non. Or biendôt il la rattrape, musclé, violent, et la saisit, la serre dans ses bras, la renverse, l'immerge entièrement pendant quelques battements de coeur. Ou peut-être est-ce un texte qui rêve? (p. 145).

Este segmento envia à primeira novela:

Jeu

jeune femme brune

corps pris

elle implore

- Cosimo!

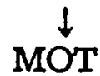

P.B.

jeune femme brune corps pris

Elle crie

non

$\downarrow$

NOM

Ulvas fazem parte do lixo amontoado (p. 150). O texto apresenta, como em S.P., o par ulves /valves e sua conse-

32 KRIgTEVA. J. Bémiotique: recherches pour une sémanalsse. Paris, Beull, 1969. p. 184. 
quiente significação vulvar. O signo volve, implicito, pode juntar-se à série paronomástica (ulves / valves / vulve / volve), sobredeterminado por várias relações: homófono do lat. volva (vulva) e anagrama de volvere (revolver, percorrer - o personagem "remue d'une main, avec précaution, la prometteuse diversité", p. 147), conota o movimento translinear referido na trajetória do rastelo; associado à idéia de cogumelo (trata-se da membrana que o envolve), é sugerido pela figura dos guarda-sóis ( $G$. fala de guarda-chuvas, $p$. 137), que remonta a crithmes, planta umbelífera de "Jeu" (p. 15).

Como existe um gênero de cogumelo que em botânica se chama phallus, ${ }^{33}$ os guarda-sóis com ele relacionados traem o ato da penetraçāo: "c'est lui imposant un mouvement circulaire qu'il enfonce chacun, profondément..." (p. 151).

O estranho rastelo também se torna um elemento sexual, associado ao ato da inscrição, verdadeiro defloramento da página virgem:

Entre la double bordure de ce qui échappe par côté, le sable s'étale en une surface vierge... Comme la progression s'accomplit par saccades, l'apparente horizontalité du sol se compose à vrai dire d'anticlinaux miniatures (p. 146, grifos nossos).

A violência é discretamente sugerida:

Et il le tire peniblement, à reculons. Il n'est pas à mi-parcours que, déjà brillantes, ses épaules dessinent chacune un croissant de soleil. Bientôt une coulée descend, entre les omoplates, jusqu'au bleu délavé du short (p. 146).

Um trocadilho desvela a "souillure": "une coulée descend! une coulée de sang.

E nos parênteses do texto (C'est une parenthèse", "déchirure nouvelle", p. 148; "lacunes", p. 149; "espace blanc à chaque fois", p. 152), pode-se reconhecer a imagem fantasmática da mãe e a transgressão do interdito maior:

"Douce, continue, la grande image de la mer" ( $p$. 147).

Com esta inseminação de sentidos, a escritura produz uma "approximative bulle" e uma criança (p. 152), ligadas à imagem uterina.

33 AUOE. v. 5. p. 524. 
Tal rede de relações imaginárias não pode ser negada, conforme parece dizer o texto por anagramas e trocadilhos (panier d'osier / reseau pas nié), interrogaçōes ("est-ce un texte qu rêve?, p. 145) ou quase explicitamente:

Le vocabulaire se donnerait alors un tout autre ordre que celui où peu à peu se forme, à la clarté déclinante, avec ses lacunes, son mouvement, ses obscurités et sa lumière, la figure d'un texte ( $p$. $153)$.

A novela termina com a proclamaçāo de sua única substância: a palavra (non: nom). Inscrevendo iconicamente a última página, termina com a imagem da escrita tingindo parte da folha e deixando a outra em branco, à mercê de uma provável continuação do texto. Impossivel não ler aqui o intertexto de Mallarmé, na utilização significante do espaçamento e nos signos (com grifos nossos) de "Un coup de dés":

Elle crie non, non, non.

Si bien que, sauf improbable découverte ultérieure, subsiste seule, en ce lieu, maintenant, ensevelie par l'ombre, toute une marge blanche (p. 155).

\section{9. "Autobiographie"}

O título anuncia um tipo de narração testemunhal que força o emprego da primeira pessoa. Sob este aspecto, a última novela se liga à primeira: "Jeu" relata a sua própria feitura ( jeu / je) e desencadeia os textos subseqüentes; "Autobiographie" (A.) é uma volta aos textos anteriores, um amplo movimento de translaçāo em torno de toda uma produção ficcional.

Extrapolando o circulo das Révolutions Minuscules para afirmar-se como uma espécie de sintese dos três romances de Ricardou, A. declara seu cunho autobiográfico através de uma engenhosa fantasia: a partir das manchas sugestivamente geográficas que um tinteiro derramado produz sobre a mesa de trabalho - "desastre obscuro" convocando o intertexto mallarmaico, ${ }^{3+}$ a novela se constrói e integra num mapa-mundi os textos anteriores. Mas, não é o mapa que engendra o texto e, sim, o contrário. Trata-se de uma autobiografia dissimulada pela geografia. Vejamos alguns exemplos.

34 Mallarmat, 8. Le tombeau d'Edgar Poe e Quant au livre. In: Oouvres compldtea, p. 70 e 370 . 
A região nórdica da Europa propōe a leitura de uma curiosa figura: o rosto e as espáduas de uma mulher ajoelhada são o golfo de Botnie; seu livro, o golfo da Finlândia. Kanin, ao norte da Rússia, é a cabeça de um guerreiro "étrangement casqué", cujo olhar, prolongando-se para além do Mar Branco em sua frente, vem pousar no livro. Se esta linha visual continuar, passa por Veneza e chega até a Córsega. Se, por outro lado, o olhar da leitora atravessar o livro, encontrará a Criméia, o Mar Negro, a Ásia na Turquia, depois a Palestina e o Alto Egito (p. 164).

Aproximados pela metáfora do papel e da tinta, o mar Branco e o mar Negro se encontram necessariamente, produzindo a reflexão sobre a gênese de um texto. O testemunho refere-se a La Prise de Constantinople ( $p$. 164-166), bizantino texto onde o relato pulverizado da quarta cruzada (evocada em A. pela citação de Veneza, da Turquia e da Palestina) se entrelaça a uma estória de pirataria espacial ("La prise de la constellation") e à escritura do próprio texto ("La prose de Constantinople"). A leitora ajoelhada remete às repetições incessantes da pose de Isabelle / Alice e à leitura de um "livro singular" (o próprio romance e, em A., um livro líquido, isto é, o golfo da Finlândia). O guerreiro formado pela ilha de Kanin associa-se então à versão bélica de La Prise de Constantinople e, através da homofonia Kanin / canin, ao cão de Procris e a Orion, o cãozinho de "Jeu".

Botnie é um anagrama de bientôt, que compõe a série paranomástica bientôt / sitôt / tôt: "Pourtant, bientôt, ces peninsules s'accroissent" (p. 162); Bientôt subsisteront seuls..." (p. 169); "Et sitôt revenu sous le ciel bleu par les rues poussiéreuses..." ( $p .163$ ); "une ligne trop tôt inter. rompue..." (p. 164). Além de fornecer material lexical à novela, a série evoca Thot, deus egipcio considerado inventor da escrita. Tal conotação mitológica reforça a referência ao Egito, introduzida no texto pelo prolongamento da linha visual feminina. O rio Nilo, então, desvela a isotopia da escritura. Nil (p. 165) é um anagrama de lin, fibra têxtil. A ligaçāo entre Nil e Finlande realizada aparentemente pela linha do olhar, descobre um tecido fônico e semântico:

\section{NIL $/$ LIN $=$ FIL \\ LIN + FIL = FINLande}

Do contexto egípcio, os colossos de Memnon - meta. morfoses da gigantesca estátua de In. (p. 50) estabelecem uma série de relações: a mutilação da estátua, associada à morte de Osiris, produz a correspondencia com Thot (res- 
ponsável pela ressurreição do deus esquartejado), ${ }^{35}$ numa auto-referenciação do texto como corpo fragmentado por significaçōes múltiplas e translineares; Memnon e seu trocadilho même nom referem-se à lei que fundamenta esta escritura, a lei da analogia, sintetizada no provérbio "Qui se ressemble s'assemble", formulado nas entrelinhas: "l'itinéraire où les fragments épars se rassemblaient ressemblait fort $[\ldots]$ à celui de la quatrième Croisade" (p. 165; grifos nossos).

D'autres histoires, à leur manière, venaient greffer leurs détours sur ces axes croisés. De l'une, je sais seulement q'un protagoniste, dont le nom déguisait à peine l'adjectif "russe", était censé dis paraître sur la route d'un Etat balte... (p. 166).

Trata-se de Albert Crucis, protagonista de Les lieux-dits, misterioso pintor desaparecido num desastre de automóvel na regiāo báltica. A vocaçāo do personagem deve-se a um fator etimológico: crucis, genitivo latino, significa "de la croix" e, por trocadilho, "Delacroix". Cicrus, anagrama de Crucis, é entendido como sic russe, "textualmente russo". Assim, a intertextualidade e a operação fônica re-inscrevem o norte europeu na topografia da novela.

L'Observatoire de Cannes é mencionado como uma estória que "exaltait ce côté belvédère d'où, parait-il, on voit, sous certaines conditions, se profiler la Corse" (p. 166).

Corse é o resultado de uma paulatina metamorfose fônica: courses / écorces / corse ( $p$. 160 e 163). O verbo corser é duplamente conotado: seu significante é indicado pela homofonia com o substantivo Corse; seu significado (tomar corpo) é fornecido pelo próprio texto: "Avec les déplacements du doigt [ . . ] prend corps l'idée d'un continent unique..." (p. 162; grifos nossos). A semelhança de significante, gerando a semelhança de significado entre Corse e corps, e depois o cruzamento rousseliano com Sardaigne produzem um "corps qui saigne" (COR + SardAIGNE). Nesta rede de relações, Crimée aponta o crime.

A estranha antonomásia da Córsega, "la souillure" ( $p$. 164), relaciona-se com a mancha provocada pelo tinteiro derramado sobre a folha de papel; "son angle supérieure, à gauche, est souillé d'une macule irrégulière" (p. 161; grifos nossos).

Assim, a partir de uma "brutale intuition" (p. 164) que lê no nome das ilhas um corpo sangrando e que confere à 
mancha sobre a página virgem ("pages vierges ou raturées", p. 161) conotação criminal e incestuosa, surge a versão geográfica do "corps pris", na figura feminina designada metonimicamente pela cabeleira, "au-delà de la table, dans la profondeur de la chambre" (p. 162).

Aglutinando, numa variante, imagens de P.B. (a. a limpeza da praia; $b$. "Sans doute les oiseaux du large ont-ils laissé sur les ondulations fragiles [...] le fin graphisme de leurs traces", p. 143-144) e de "Jeu" ("elle s'enfuit en tous sens sur la page, parmi les coquilles, au risque de se perdre, à la poursuite de quelque nouveau jeu", p. 31), A. termina com a limpeza de um jardim, anunciando um novo texto: - solo limpo, no qual se acumula "en ébauches de tours" (novas construções esboçadas) um material a ser reutilizado ("feuilles et plumes éparses"), é o espaço onde a es. critura continuará a complicar-se infinitamente:

Ce sera au prix, sur le sol, d'insignifiantes courbes que viendront compliquer, peu à peu, en tous sens, infiniment, des empreintes d'oiseaux (p. 170).

\section{RESUME}

Cette étude veut montrer l'auto-génération et les principales isotopies d'un recueil de neuf nouvelles enchainées - les Révolutions Minuscules, de Jean Ricardou.

Des procéciés fondés sur la polysémie ct l'anagramme engendrent un texte qui déclenche à son tour d'autres textes. La rotation des mots se prolonge dans un mouvement de translation réalisé par la migration des signes qu'une irrégularité réforme d'une nouvelle à l'autre.

Le jeu des connotations reflète trois isotopies entre. croisées: l'isotopie constellaire - perçue à travers le méca. nisme sidéral de la révolution des signes, l'isotopie de l'écriture - quand le texte exhibe sa propre construction et en fait son histoire, et l'isotopie sexuelle ou l'écriture du corps - inter-dite dans les brisures du tissu textuel.

\section{REFERENCIAS BIBLIOGRAFICAS}

1 AUGE, P. Dictionnaire Larousse du XXe. siècle. Paris, Larousse, 1928. $6 \mathrm{v}$.

2 BARTHES, R. Le plaisir du texte. Paris, Seuil, 1973. 108 p.

3 CHEVALIER, J. \& GHEERBRANT, A. Dictionnaire des symboles. Paris, Seghers, 1969. 4 v. 
4 DERRIDA, J. La dissemination. Paris, Seuil, 1972. 407 p.

5 -.... Marges de la philosophie. Paris, Minuit, 1972. 393 p.

6 Positions. Paris, Minuit, 1972. $133 \mathrm{p}$.

7 GREIMAS, J. \& COUTES, J. Sémiot:que: dictionnaire raisonné de la théorie du langage. Paris, Hachette, 1979. 423 p.

8 GRIMAL, P. Dictionnaire de 13 mythologic. 6. éd. Paris, Presses Universitaires de France, 1979. $574 \mathrm{p}$.

9 KRISTEVA, J. Sémiotique; recherches poirr une sémanalyse. Paris, Seuil, 1969. $380 \mathrm{p}$.

10 LACAN, J. Ecrits. Paris, Seuil, 1966. 924 p.

11 LEVI-STRAUSS, C. Le cru et le cuit. Paris, Plon, 1964. p. 203-87.

12 MALLARME, S. Oeuvres complètes. Paris, Gallimard, 1945. 1659 p.

13 PAZ, O. Signos em rotaçāo. São Paulo, Perspectiva, 1976. 320 p.

I4 RICARDOU, J. Les lieux-dits. Paris, Gallimard, 1969. 160 p.

15 Nouveaux problèmes du roman. Paris, Seuil, 1978. $351 \mathrm{p}$

16 Lobscrvatoire de Cannes. Paris, Minuit, 1961, 160 p.

17 La prise de Constantinople. Paris, Minuit, 1965. n.p.

18 . Révolutions minuscules. Paris, Gallimard, 1971. $170 \mathrm{p}$.

19 ROBERT, P. Dictionnaire alphabétique et analogique de la Iangue frança:se. Paris, Société du Nouvcau Littré, 1970. 1971 p. 